\section{On the paper trail}

\section{The National Science Foundation's efforts to audit time-keeping could serve a useful purpose.}

$G^{\prime}$ riping about the paperwork involved in grant proposals is a popular pastime in academia. And there will doubtless be plenty more complaints in the United States as the National Science Foundation (NSF) launches an audit of how accurately researchers at 30 universities report the time spent on their research projects - a practice known as 'effort reporting' (see page 512).

US scientists already do plenty of bookkeeping on their federal grants, and the NSF's more rigorous requirements for them to account for their time are unlikely to be well received. Science, after all, thrives on researchers being free to explore fresh avenues of discovery without being hampered by too much bureaucracy. A careful balance must be struck between agencies and the scientists to whom they provide grant money, based on a degree of trust that funds will be used honestly and for the purposes described in the grant application.

Yet the NSF, with a budget of $\$ 6$ billion, is now a major agency with a responsibility to the public to account for how that money is spent. So scientists should cooperate generously with the new audits, even if they cannot learn to love them.

Relatively little is known about how researchers spend their time using grant money. The NSF is trying to ensure that universities are supervising their researchers sufficiently and are thus avoiding flagrant abuse of the funding system. Two initial audits have uncovered sloppy record-keeping that could hint at a bigger problem. Auditors have found, for instance, that researchers say they expect to devote a certain percentage of their time on a particular grant-funded project, but then fail to keep track of the hours they actually do spend on it.

The NSF hasn't decided to conduct the audits arbitrarily. Whistle- blowers at two universities highlighted cases in which researchers failed to tell the National Institutes of Health $(\mathrm{NIH})$ about the amount of time they spent on projects it had funded. The universities involved subsequently repaid the money.

In the coming weeks, the NSF will finalize and release audits of five more major universities: these may bring to light further problems in the time-reporting system. As scientists complain about tight budgets and more competition for award money, they should support efforts to make sure that money is tracked accurately.

Faced with the paperwork involved in each grant application, and unsure of the details of how each project will actually pan out, researchers are often inclined to leave blank the line that requests an estimate of how much time they will spend on the project. But they should make every effort to provide this figure. It could, for instance, cut down on the number of unfortunate instances in which researchers over-commit to various proposals, and then fail to spend enough time on any of them.
"Scientists should support efforts to make sure that money is tracked accurately." Eliminating this kind of overload should also help ensure that graduate students and postdocs get adequate guidance from their supervisors.

According to NSF auditors, grant reviewers are likely to start paying more attention to effort reporting on applications within the next few grant cycles. This would be a welcome development. Congress should give the NSF inspector-general's office the money it says it needs to hire more auditors. The NSF should not, of course, go overboard in persecuting competent researchers for minor violations of bureaucratic standards. But it should try to raise the level of compliance in effort reporting.

These NSF efforts may, in time, serve as an instructive template for the NIH, a far larger agency that has done little as yet to monitor its grantees' effort reporting. With so much money at stake, a little extra paperwork is not necessarily a bad idea.

\section{Living with the heat}

\section{Science and politics need to engage more than ever.}

\/ hether face-to-face with a president or prime minister, or participating in public consultations, scientists interacting with politics must cope with two major challenges. They are likely to encounter a degree of unfamiliarity with science and the way it works that requires all their skills to convey crisply what they know in a way best attuned to their listeners. At the same time they will soon realize that those with whom they are engaging are not only in the driving seat but often have constraints, values and goals that the scientists need to understand and, where appropriate, to which they must adapt.

Throughout history, individual scientists have found themselves in direct dialogue with politicians, and have encountered the full range of acceptance, hostility, knowledge deficits, political judgement and dilemmas. Some find themselves in discussion with other stakeholders in assessing policy issues. The recent UK nanotechnology dialogues

(see Nature 448, 1-2; 2007) illustrated the virtues of engagement in a number of local contexts. They also showed how much both scientists and others can learn from such engagements, whether about the realities of African villages, public values or what science itself may be able to contribute.

Whether in planning future agriculture (see page 518) or in responding to potential disasters, scientists find themselves increasingly involved in political processes. This is as it should be. And not all scientists are 'natural'. Social scientists can also bring a great deal to the table, in analysing people's attitudes and behaviours.

Nature will fully explore these sorts of engagements in a series of essays, 'Science and politics', launched this week by Richard Garwin (see page 543). His account of the decline in mechanisms for providing the US government with scientific advice is pessimistic, if all too timely. More upbeat is next week's dispatch from Hans Wigzell about the changes he wrought to stem-cell policy-making in Sweden by enthusing ministers about research. And we promise that the series will end with a sense of confident affirmation of the virtues of rationality. Mindful of President Harry S. Truman's advice, scientists need to stay in the kitchen, recognizing how hot it can get. 